\title{
DETECTION OF AUTISITC LIKE TRAITS IN PATIENTS WITH SCHIZOPHRENIA AND BIPOLAR DISORDERS
}

\author{
Khadija Emad Dawoud, Yasser Mohamed Raya, Amira Mohamed Yossef, Abdullah Saad \\ Ibrahim \\ Department of psychiatry, Zagazig university hospital, Zagazig, Egypt
}

Received: 3 October 2018

Accepted: 21 December 2018

Corresponding Author

Khadija Emad Dawoud

khadijadawoud4@gmail.com

\section{ABSTRACT}

Background: Autism spectrum disorder often co-occurs with other psychiatric disorders. Although a high prevalence of autistic-like traits/symptoms has been identified in the pediatric psychiatric population of normal intelligence, there are no reports from adult psychiatric population.

Subjects and methods: The subjects were 78 adults of normal intelligence between 18 and 60 years of age (bipolar disorder, $n=26$; schizophrenia, $n=26$; healthy controls, $n=26$ ). Autistic-like traits/symptoms were measured using the Autism Spectrum Quotient (AQ) for adults. Symptom severity was measured using the Positive and Negative Symptoms Scale, the Hamilton Depression Rating Scale, and/or the Young Mania Rating Scale.

Results: schizophrenic patients had higher level of autistic traits than bipolar patients and healthy control. On the other hand, bipolar patients had similar level of autistic traits as that of healthy control.

Conclusion: These findings suggest the importance of evaluating autisticlike traits/symptoms underlying adult-onset psychiatric disorders for the bestsuited treatment. Further studies with a prospective design and larger samples are needed.

Key words: autism; schizophrenia; bipolar.

\section{INTRODUCTION}

A utism spectrum disorder (ASD) is an early-onset, life-long developmental disorder characterized by persistent deficits in social reciprocity and social communication, as well as restricted, repetitive patterns of behaviors, interests, or activities ${ }^{(1)}$. Autistic like traits (ALTs) are the "sub-threshold" ASD symptoms or traits (also measured by quantitative ASD symptom scales). ALTs refer to the presence of ASD symptoms at the time of assessment but may lack evidence or assessment of their presence in childhood ${ }^{(2)}$. Schizophrenia is a common psychiatric disorder, marked by gross distortion from reality; disturbances in thinking, feeling, and behavior $^{(3)}$. Schizophrenia is estimated to be $1 \%$ of population ${ }^{(4)}$ and ASD may present a risk factor for the development of schizophrenia $^{(5)}$. Bipolar disorder (BD) is a major affective disorder characterized by chronically recurring episodes of mania (or hypomania) and depression, which in their severe forms may present with psychotic symptoms, such as hallucinations or delusions $^{(6)}$. There is an overlap between January 2019 Volume 25 Issue 1
Autism, schizophrenia and bipolar disorders genetically as they show an overlap between the genetic loci and even alleles that predispose to the different phenotypes ${ }^{(7)}$ and clinically as they share common behavioral characteristics and cognitive deficits ${ }^{(8)}$. The prevalence of ASD is estimated to be approximately $1 \%$ of the population ${ }^{(9)}$ and it is well documented that individuals with a diagnosis of ASD are predisposed to a variety of other mental health difficulties and comorbidities such as mood disorders, schizophrenia ${ }^{(\mathbf{1 0})}$. On the other hand, frequent co-occurrence of ASD among psychiatric patients has been identified in several studies of clinical youth aged 7-17 years that had been diagnosed with mood disorder. Pine et al., (11) observed that $57 \%$ of youth patients with BPD exceeded the clinical cut-off for quantitative ASD scales. Although a high prevalence of autistic-like traits/symptoms has been identified in the pediatric psychiatric population of normal intelligence, there are no reports from adult psychiatric population ${ }^{(12)}$. A study in Japan showed that there is an increase in number of adults with ALTs who 
visit general psychiatric clinics seeking accurate diagnosis and/or treatment for concurrent psychiatric symptoms ${ }^{(13)}$. This study examined whether there is a greater prevalence of autistic-like traits/symptoms in patients with adult-onset psychiatric disorders such as bipolar disorder or schizophrenia and whether such an association is independent of symptom severity.

\section{SUBJECTS AND METHODS}

Subjects were 78 adults aged 18 to 60 years. They consisted of 26 patients with SZ, 26 with BPD and 26 healthy controls (HC). They were randomly selected from inpatient and outpatient of psychiatry department of ZUH. All subjects were interviewed by a trained psychiatrist using semi-structured questionnaire which designed to collect sociodemographic data as age, sex, residence and marital status, clinical data as age of onset of disease, duration of illness and number of hospitalization, history of any operations and history of other medical or psychiatric disorders. Diagnoses were confirmed based on the DSM of Mental Disorders, 5th ed. (DSM-V). All participants were subjected to Autism Spectrum Quotient (AQ). Schizophrenic symptoms were corroborated by administering the Positive and Negative Symptoms Scale (PANSS) to all subjects with SZ. Depression severity was assessed using the 17-item version of the Hamilton Depression Rating Scale (HDRS-17) and manic symptoms were assessed by the Young Mania Rating Scale (YMRS) for all subjects with BPD. Subjects with BPD whose YMRS total scores were 8 or over were considered to be suffering from a significant manic state and excluded from this study. Subjects with SZ should score for all of the following items under 4 to be included in the study: delusion, conceptual disorganization, hallucinatory behavior, blunt affect, passive apathetic social withdrawal, lack of spontaneity and flow of conversation, mannerisms and posturing, unusual thought content. Those already given a clinical diagnosis of ASD were excluded. In addition, those who had intellectual disability were excluded. Full-scale IQs were assessed using the Wechsler Adult Intelligence Scale (WAIS). Approval was obtained from the Institutional Review Board (IRB). Written informed consent was obtained from all participants prior to their inclusion in the study.

Autism-Spectrum Quotient (AQ):

It is self-reported questionnaire consisted of 50 questions. It is divided into 5 subscales of 10 questions each. The 5 subscales are: Social Skill, Attention Switching, Attention to Details, Communication and Imagination. On the whole, the items ask the respondent to agree or disagree with statements about personal preferences and habits. Each of the items scores 1 point if the respondent records the abnormal or autistic-like behavior either mildly or strongly. Approximately half the items were worded to produce a 'disagree' response, and half worded to produce an 'agree' response, in a high scoring person with Asperger Syndrome (AS).

Positive and negative Symptoms Scale:

Positive and Negative Syndrome Scale (PANSS) is among the best-validated instruments for assessing positive, negative, and general psychopathology associated with schizophrenia. The PANSS is a standardized, clinical interview that rates the presence and severity of positive and negative symptoms, as well as general psychopathology for people with schizophrenia within the past week. Of the 30 items, seven are positive symptoms (score range 7-49), seven are negative symptoms (score range 7-49), and 16 are general psychopathology symptoms (score range 16-112). Symptom severity for each item is rated according to which anchoring points in the 7-point scale $(1=$ absent; $7=$ extreme) best describe the presentation of the symptom. PANSS showed good reliability and good internal consistency ${ }^{(\mathbf{1 4})}$.

3-Hamilton Depression Rating Scale.

The Hamilton Depression Rating Scale is the most widely used interview scale to assess severity of depression. It is composed of 21 items that assess Depressed mood, Feelings of guilt, Thoughts of suicide, Insomnia, Work and activities, Psychomotor retardation, Psychomotor agitation, Psychic anxiety, Somatic anxiety, Gastrointestinal symptoms, General somatic symptoms, Genital symptoms, Hypochondriasis, Loss of insight, Loss of weight, Diurnal variation, Depersonalization and derealization, Paranoid 
symptoms, Obsessional and compulsive symptoms. The first 17 items are tallied for the total score, while items 18-21 are used to further qualify the depression. The scale takes 20-30 minutes to administer. Scores of 0-7 are considered normal, and scores greater than or equal to 20 indicate moderately severe depression. Each item either is scored on a 5point scale, representing absent, mild, moderate, or severe symptoms, or on a 3point scale, representing absent, slight or doubtful, and clearly present symptoms ${ }^{(15)}$.

\section{4-Young Mania Rating Scale:}

The Young Mania Rating Scale (YMRS) is most commonly used standardized measure of bipolar manic symptoms in acute mania clinical trials. The scale has 11 items and is based on the patient's subjective report of his or her clinical condition over the previous 48 hours. Additional information is based upon clinical observations made during the course of the clinical interview. The items are selected based upon published descriptions of the core symptoms of mania. The YMRS follows the style of the Hamilton Rating Scale for Depression (HAM-D) with each item given a severity rating. There are four items that are graded on a 0 to 8 scale (irritability, speech, thought content, and disruptive/aggressive behavior), while the remaining seven items are graded on a 0 to 4 scale. These four items are given twice the weight of the others to compensate for poor cooperation from severely ill patients ${ }^{(16)}$.

\section{RESULTS}

Table 1 Studying of demographic data among the studied groups.

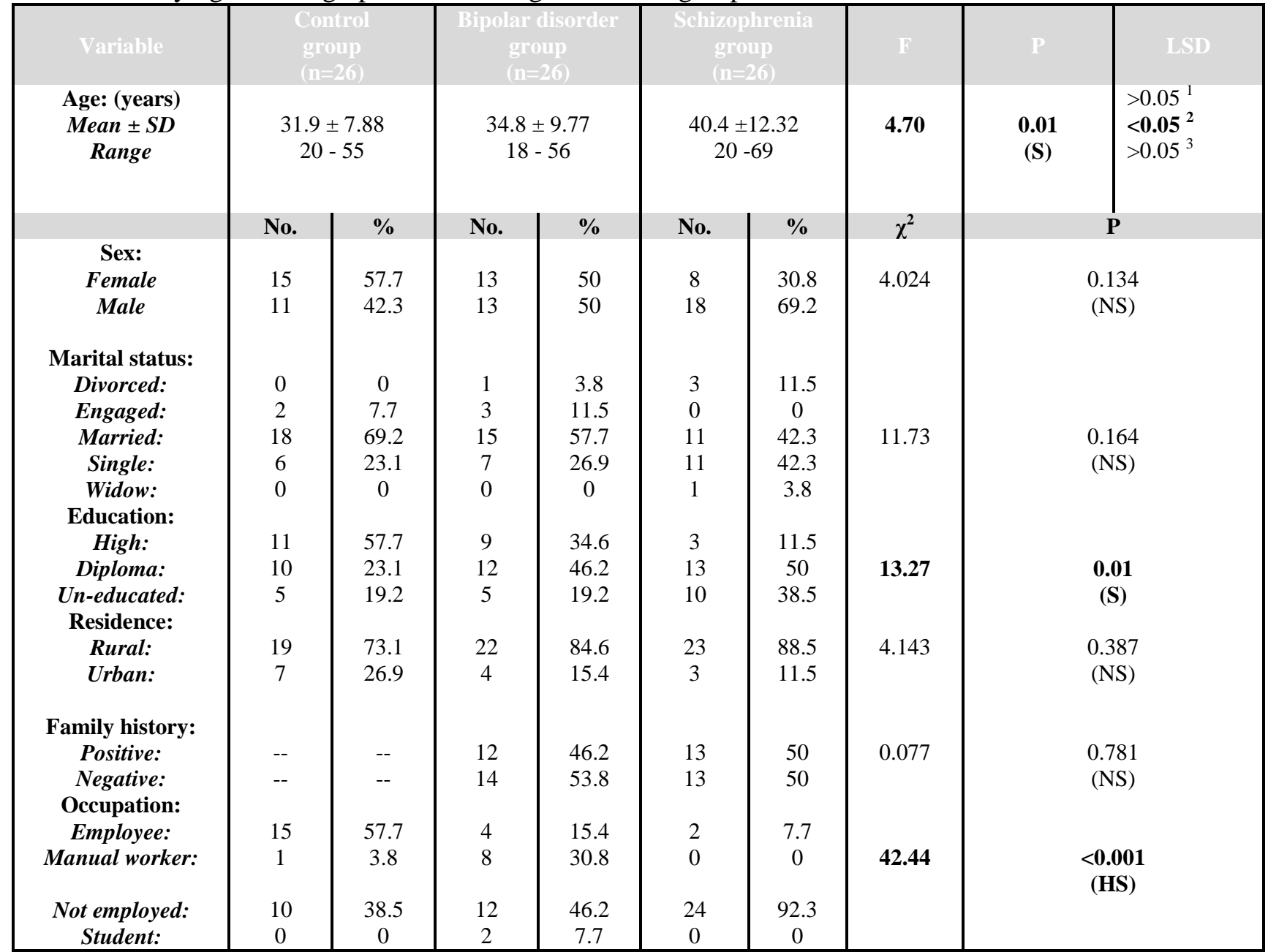

LSD: Least significant post hoc test

P1: control versus bipolar disorder groups.

P2: control versus schizophrenic groups.

P3: bipolar disorder versus schizophrenic groups.

F: one way ANOVA. 


\section{Dawoud et al}

This table shows that there was non-significant difference between the studied groups as regarding sex, residence, family history and marital status ( $p>0.05$ ).

There was significant difference as regarding age $(p<0.05)$. This difference is between control group and schizophrenia group.
Zagazig University Medical Journals

There was significant difference as regarding education noticing that lowest level of education was among schizophrenic group.

There was a highly significant difference as regarding occupation $(\mathrm{p}<0.001)$ with highest number of not employed is among schizophrenia group.

Table 2 Comparison of autistic quotient (AQ) among the studied groups

\begin{tabular}{|c|c|c|c|c|c|c|}
\hline Variable & $\begin{array}{l}\text { Control } \\
\text { group } \\
(n=26)\end{array}$ & $\begin{array}{l}\text { Bipolar disorder } \\
\text { group } \\
(n=26)\end{array}$ & $\begin{array}{l}\text { Schizophrenia } \\
\text { group } \\
(n=26)\end{array}$ & Test & P & LSD \\
\hline $\begin{array}{c}\text { AQ: } \\
\text { Mean } \pm \text { SD } \\
\text { Median (Range) }\end{array}$ & $\begin{array}{c}16 \pm 5.19 \\
15.5 \\
8-24\end{array}$ & $\begin{array}{c}15.8 \pm 5.13 \\
15.5 \\
6-29\end{array}$ & $\begin{array}{c}28.3 \pm 3.09 \\
28.5 \\
21-32\end{array}$ & 50.81 & $\begin{array}{c}<0.001 \\
(\text { HS })\end{array}$ & $\begin{array}{l}>0.05^{1} \\
<0.05^{2} \\
<0.05^{3}\end{array}$ \\
\hline $\begin{array}{c}\text { Social skills: } \\
\text { Mean } \pm S D \\
\text { Median } \\
\text { Range }\end{array}$ & $\begin{array}{c}3.34 \pm 2.26 \\
2.5 \\
1-7\end{array}$ & $\begin{array}{c}3.07 \pm 2.65 \\
3 \\
0-10\end{array}$ & $\begin{array}{c}7.92 \pm 2.65 \\
8 \\
5-10\end{array}$ & 40.22 & $\begin{array}{c}<0.001 \\
(\mathrm{HS})\end{array}$ & $\begin{array}{l}>0.05^{1} \\
<0.05^{2} \\
<0.05^{3}\end{array}$ \\
\hline $\begin{array}{l}\text { Attention switch: } \\
\text { Mean } \pm S D \\
\text { Median } \\
\text { Range }\end{array}$ & $\begin{array}{c}4.34 \pm 1.16 \\
4 \\
3-7\end{array}$ & $\begin{array}{c}4.34 \pm 1.74 \\
5 \\
0-7\end{array}$ & $\begin{array}{c}4.53 \pm 1.81 \\
4 \\
2-9\end{array}$ & 0.125 & $\begin{array}{c}0.883 \\
(\mathrm{NS})\end{array}$ & $\begin{array}{l}>0.05^{1} \\
>0.05^{2} \\
>0.05^{3}\end{array}$ \\
\hline $\begin{array}{c}\text { Attention to detail: } \\
\text { Mean } \pm S D \\
\text { Median } \\
\text { Range }\end{array}$ & $\begin{array}{c}3.53 \pm 2 \\
4 \\
1-8\end{array}$ & $\begin{array}{c}2.92 \pm 1.95 \\
3 \\
0-8\end{array}$ & $\begin{array}{c}2.26 \pm 1.37 \\
2.5 \\
0-4\end{array}$ & 3.227 & $\begin{array}{c}\text { 0.04 } \\
(\mathrm{S})\end{array}$ & $\begin{array}{l}>0.05^{1} \\
<\mathbf{0 . 0 5}{ }^{2} \\
>0.05^{3}\end{array}$ \\
\hline $\begin{array}{c}\text { Communication: } \\
\text { Mean } \pm S D \\
\text { Median } \\
\text { Range }\end{array}$ & $\begin{array}{c}2.42 \pm 2.02 \\
2 \\
0-7\end{array}$ & $\begin{array}{c}2.73 \pm 1.58 \\
2.5 \\
0-6\end{array}$ & $\begin{array}{c}6.80 \pm 1.23 \\
7 \\
4-10\end{array}$ & 57.39 & $\begin{array}{c}<0.001 \\
(\mathrm{HS})\end{array}$ & $\begin{array}{l}>0.05^{1} \\
<0.05^{2} \\
<0.05^{3}\end{array}$ \\
\hline $\begin{array}{c}\text { Imagination: } \\
\text { Mean } \pm S D \\
\text { Median } \\
\text { Range }\end{array}$ & $\begin{array}{c}2.84 \pm 1.51 \\
3 \\
0-5\end{array}$ & $\begin{array}{c}3.46 \pm 1.60 \\
3 \\
1-7\end{array}$ & $\begin{array}{c}6.53 \pm 1.30 \\
7 \\
4-9\end{array}$ & 46.44 & $\begin{array}{c}<0.001 \\
(\text { HS })\end{array}$ & $\begin{array}{l}>0.05^{1} \\
<\mathbf{0 . 0 5}{ }^{2} \\
<0.05^{3}\end{array}$ \\
\hline
\end{tabular}

\section{Test: kruskall-wallis test.}

This table shows that there was highly significant difference between the studied groups as regarding $\mathrm{AQ}$, social skills, communication and imagination traits $(\mathrm{p}<0.001)$. This significant difference is between schizophrenia group when compared with the other two groups, bipolar group and control group. There was non- significant difference between control group and bipolar group.

There was significant difference between the studied groups as regarding attention to detail. This difference is between control group and schizophrenia group. There was non- significant difference between bipolar and other two groups. However, there was non-significant difference among them as regarding attention switch trait. 
Table 3 Relation between AQ and different parameters among the bipolar disorders studied group

\begin{tabular}{|c|c|c|c|c|c|}
\hline Variables & N. & Mean & SD & test & p-value \\
\hline $\begin{array}{c}\text { Impairment: } \\
\text {-No: }\end{array}$ & 18 & 15.44 & 4.43 & & \\
-Occupational: & 2 & 14.50 & 4.94 & 0.356 & 0.704 \\
-Social and & & & & & $(\mathrm{NS})$ \\
occupational: & 6 & 17.33 & 7.47 & & \\
\hline $\begin{array}{c}\text { Compliance: } \\
\text { Compliant: }\end{array}$ & 16 & 15.12 & 4.73 & -0.854 & 0.402 \\
Non-compliant: & 10 & 16.9 & 5.80 & & (NS) \\
\hline $\begin{array}{c}\text { ospitalization: } \\
\leq 3 \text { times: }\end{array}$ & 16 & 16.0 & 5.42 & 0.237 & 0.815 \\
4-13 times: & 10 & 15.5 & 4.88 & & $(\mathrm{NS})$ \\
\hline $\begin{array}{c}\text { Duration of illness: } \\
\leq 6.5 \text { years: }\end{array}$ & 13 & 16.69 & 5.25 & 0.875 & 0.390 \\
6.6-28 years: & 13 & 14.92 & 5.05 & & (NS) \\
\hline $\begin{array}{c}\text { Number of episodes: } \\
\leq 6:\end{array}$ & 20 & 16.25 & 5.15 & 0.797 & 0.433 \\
7-13: & 6 & 14.33 & 5.20 & & (NS) \\
\hline
\end{tabular}

This table shows that there was non-significant difference between AQ and impairment, compliance of treatment, hospital stay, duration of illness, and number of bipolar episodes.

It was noticed that $\mathrm{AQ}$ level was higher in those with social and occupational impairment than others, higher in non-compliant persons to treatment than those who are compliant (16.9 versus 15.12 respectively), higher in persons with short hospital stay.

Table 4 Relation between $A Q$ and different parameters among the schizophrenic studied group

\begin{tabular}{|c|c|c|c|c|c|}
\hline Variables & N. & Mean & SD & t-test & p-value \\
\hline $\begin{array}{l}\text { Impairment: } \\
\text {-Social: } \\
\text {-Social and } \\
\text { occupational: }\end{array}$ & $\begin{array}{c}1 \\
25\end{array}$ & $\begin{array}{r}30.0 \\
28.20\end{array}$ & $\begin{array}{l}3.13 \\
3.09\end{array}$ & 0.317 & $\begin{array}{c}0.549 \\
(\mathrm{NS})\end{array}$ \\
\hline $\begin{array}{l}\text { Compliance: } \\
\text { Compliant: } \\
\text { Non-compliant: }\end{array}$ & $\begin{array}{l}13 \\
13\end{array}$ & $\begin{array}{l}28.23 \\
28.30\end{array}$ & $\begin{array}{l}2.71 \\
3.54\end{array}$ & -0.062 & $\begin{array}{c}0.951 \\
(\mathrm{NS})\end{array}$ \\
\hline $\begin{array}{l}\text { Hospital stay: } \\
\text { < } 3 \text { times: } \\
\text { 4-13 times: }\end{array}$ & $\begin{array}{l}14 \\
12\end{array}$ & $\begin{array}{l}28.64 \\
27.83\end{array}$ & $\begin{array}{l}2.73 \\
3.53\end{array}$ & 0.658 & $\begin{array}{c}0.517 \\
(\mathrm{NS})\end{array}$ \\
\hline $\begin{array}{l}\text { Duration of illness: } \\
\leq 13.5 \text { years: } \\
13.6-35 \text { years: }\end{array}$ & $\begin{array}{l}14 \\
12\end{array}$ & $\begin{array}{l}28.42 \\
28.08\end{array}$ & $\begin{array}{l}2.56 \\
3.72\end{array}$ & 0.278 & $\begin{array}{c}0.783 \\
\text { (NS) }\end{array}$ \\
\hline
\end{tabular}

This table shows that there was non-significant difference between AQ and impairment, compliance of treatment, hospital stay, and duration of illness.

It was noticed that AQ level was higher in those with social impairment than others, higher in noncompliant persons to treatment than those who are compliant (28.3 versus 28.2 respectively), higher in persons with short hospital stay and long duration of illness.

\section{DISCUSSION}

Unlike children diagnosed with ASD, clinical manifestations in adulthood are often complex: core symptoms tend to become less apparent ${ }^{(17)}$, or adults with ASD may use compensatory strategies to mask their deficits.
For these reasons, clinical or subclinical ASD symptoms are likely to be overlooked in general psychiatric settings, which can lead to inappropriate treatment ${ }^{(18)}$. 
We studied 26 schizophrenic patients, 26 bipolar patients and compared them with another 26 healthy control.

In the present study we tried to assess frequency of autistic like traits in bipolar and schizophrenic patients and its effect on severity of disorder.

\section{As regarding AQ:}

We found that there is a highly significant difference between schizophrenic patients $(28.3 \pm 3.09)$ and other two groups, bipolar group and healthy control group (15.8 \pm 5.13 , $16 \pm 5.19$ respectively).

There was non-significant difference between bipolar patients and healthy control.

A study of autistic like traits conducted on adult schizophrenic and bipolar patients by Matsuo et al., ${ }^{(12)}$ showed that the proportion of autistic like traits in bipolar patients (mean SRS score: 55.4) and schizophrenic patients (mean SRS score: 59.6) was significantly higher than that of healthy control (mean SRS score: 32.5 ).

Another study was conducted on adult bipolar patients only by Abu-Akel et al., ${ }^{(19)}$ showed that high levels of autistic traits in bipolar patients (mean AQ-short score: 65.02).

A study to compare ASD symptoms in healthy youths and youths with mood disorders showed also that autistic traits in bipolar patients (mean SRS score 68.7 \pm 2.7 ) was significantly higher than that of healthy control (mean SRS score 23.2 \pm 2.1$)^{(11)}$. A screening study for ASD was done in adult psychiatric outpatients (n: 1323 patients). It showed that minimum of $1.4 \%$ of sample had ASD (19 patients). Among those 19 patients there were 5 schizophrenic patients and 2 bipolar patients ${ }^{(20)}$.

This difference between our results and these papers' results regarding level of autistic like traits in bipolar patients when compared with that of healthy control may be due to our sample of bipolar patients mostly were in complete remission with YMRS score was 0 and also the AQ questionnaire is a selfreported questionnaire, so subjects might try to improve their images and didn't give honest answers.

Another explanation should be considered to answer the question why healthy control scored high in the AQ questionnaire present in a study that compared level of autistic traits in Egyptian students, England students and Japanese students. Egyptian students scored highest scores. England students mean total score of AQ was 17.6, Egyptian students was mean 22.72, Japanese students mean score on AQ was 20.7. The authors explained that by suggestion an environmental factor. It could be that certain forms of education encourage quantitative accumulation of knowledge at the expense of imagination and also at the expense of normal social activities. This seems to be the case in the Egyptian students. In such case, students would be of higher AQ total score compared to groups who are identified by their creativity and use of imagination.

There is also a possibility that the AQ is culturally biased towards normalising some British patterns of behaviour which might make behaviours from other cultures not typically normal. This could be the case especially that the Japanese student (Mean = $20.7 \& \mathrm{SD}=6.38$ ) in Wakabayashi et al., ${ }^{[21]}$ study scored differently from the British students (mean $=17.6 \& \mathrm{SD}=6.4$ ), as well as the Japanese normal adult control group (Mean $=18.5 \& \mathrm{SD}=6.21)$ compared to the British similar group $($ Mean $=16.4 \& \mathrm{SD}=$ 6.3) ${ }^{(22)}$.

There is non-significant difference between AQ and impairment, compliance of treatment, number of bipolar episodes, hospital stay, and duration of illness in bipolar or schizophrenia patients.

There is week positive correlation between AQ and score of YMRS ( $r=.277)$.

There is week negative correlation between AQ and score of HDRS ( $r=-.061)$

This is consistent with the findings of Matsuo et al. study. These findings indicate that level of autistic traits in bipolar and schizophrenic patients is not related to the severity of their disorders.

\section{As regarding AQ subscales:}

In bipolar mania patients, we found that a significant negative correlation between YMRS and attention to detail traits $(\mathrm{r}=-.681)$, communication traits $(\mathrm{r}=-.568)$. A negative correlation between YMRS and social skills $(r=-.141)$. A positive correlation between it 
and attention switch $(\mathrm{r}=.312)$, imagination $(\mathrm{r}=.061)$.

This is consistent with DSM-5 criteria of bipolar mania; distractibility and increase sociability.

In bipolar depression patients, there is positive significant correlation between HDRS and social skills $(r=.644)$, attention switch trait $(\mathrm{r}=.629)$ and communication trait $(\mathrm{r}=.734)$. This finding is consistent with DSM-5criteria of bipolar depression where there are social withdrawal and decrease concentration. A week positive correlation between HDRS and attention to detail ( $\mathrm{r}=$ $.141)$, imagination $(\mathrm{r}=.247)$.

In schizophrenic patients, we found that social skills, communication and imagination traits were significantly higher than other groups. There is a significant positive correlation between negative symptoms of PANSS and social skills $(\mathrm{r}=.463)$ and communication traits $(r=.523)$. A significant negative correlation between negative symptoms of PANSS and attention to detail trait $(r=-.422)$. A negative correlation between negative symptoms of PANSS and attention switch traits $(r=-.144)$. A positive correlation between negative symptoms of PANSS and imagination traits $(\mathrm{r}=.320)$. Week positive correlations between positive symptoms of PANSS and social skills ( $\mathrm{r}=$. 160), communication $(\mathrm{r}=.224)$ and imagination traits $(\mathrm{r}=.127)$. Week Negative correlations between positive symptoms of PANSS and attention switch $(\mathrm{r}=-.0144)$, attention to detail $(\mathrm{r}=-.245)$. This can be explained by we took in our study controlled schizophrenic patients where the negative symptoms are dominant. These finding cannot be compared with other studies as other researchers used other scales to measure the autistic traits; Matsuo et al., ${ }^{[12]}$ and Pine et al ${ }^{[11]}$ used The Social Responsiveness Scale for Adults (SRS-A), Abu-Akel et al., ${ }^{[19]}$ used Autism Spectrum Quotient-short (AQ-Short) and Nylander and Gillberg ${ }^{[20]}$ in their screening used Autism Spectrum Disorder Adult Screening Questionaire (ASDASQ).

\section{CONCLUSION}

By the end of our study, we came up with the following conclusions: 1- Schizophrenic patients have higher level of autistic traits than has general population and bipolar patients. Bipolar patients have level of autistic traits similar to that of healthy control. 2Level of autistic traits in schizophrenic and bipolar patients is not related to symptom severity suggesting pathophysiological overlap between ASD, schizophrenia and bipolar disorders.

\section{REFERENCES}

1- American Psychiatric Association DSM-5th: Diagnostic and Statistical Manual of Mental Disorders, 5th ed. Washington DC: American Psychiatric Press.2013.

2- Debbie L. Kincaida, Michael Dorisb, Ciaran Shannona, Ciaran Mulhollandb,: what is the prevalence of autism spectrum disorder and ASD traits in psychosis? A systematic review. Psychiatry Research 2017; 250: 99-105

3- Kaplan HI, Sadock BJ. Comprehensive Textbook of Psychiatry. 2015; (11th ed); 1: 300-301.

4- Bradley, E., Lunsky, Y., Palucka, A., Homitidis, S. Recognition of intellectual disabilities and autism in psychiatric inpatients diagnosed with schizophrenia andother psychotic disorders. Adv. Ment. Health Intellect. Disabil. 2011; 5: (6), 4-18.

5- Nylander, L., Lugnegard, T., Hallerbäck, M.U. Autism spectrum disorders and schizophrenia spectrum disorders in adults- Is there a connection? A literaturereview and some suggestions for future clinical research.Clin. Neuropsychiatry 5 2008; (1): 43-54.

6- Weissman, M.M., Bland, R.C., Canino, G.J., Faravelli, C., Greenwald, S., Hwu, H.G., et al. Cross-national epidemiology of major depression and bipolar disorder. JAMA 1996; 276: (4), 293-299.

7- Carroll LS and Owen MJ. Genetic overlap between autism, schizophrenia and bipolar disorder, Genome Medicine 2009; 1: 102.

8-Craddock N, O'Donovan MC, Owen MJ. The genetics of schizophrenia and bipolar disorder: dissecting psychosis. J Med Genet, 2005; 42: 193-204.

9-Brugha, T.S., McManus, S., Bankart, J., Scott, F., Purdon, S., Smith, J., Bebbington, P.,Jenkins, R., Meltzer, H. Epidemiology of autism spectrum disorders in adultsin the community in England. Arch. Gen. Psychiatry 2011; 68: 459-465.

10- Mazefsky CA, Oswald DP, Day TN, Eack SM, Minshew NJ, et al. : ASD, a psychiatric disorder, or both? Psychiatric diagnoses in adolescents with high-functioning ASD. J Clin Child Adolesc Psychol 2012; 41(4): 516-23. 


\section{Dawoud et al}

11- Pine DS, Guyer AE, Goldwin M, Towbin KA and Leibenluft E. Autism spectrum disorder scale scores in pediatric mood and anxiety disorders. J Am Acad Child Adolesc Psychiatry 2008; 47(6): 652-61.

12- Matsuo J, Kamio Y, Takahashi H, Ota M, Teraishi T, Hori H, Nagashima A, Takei R, Higuchi T, Motohashi N, Kunugi H. Autisticlike traits in adult patients with mood disorders and schizophrenia. PLoS One. 201510 (4): e0122711.

13- Kamio Y, Inokuchi E. Psychiatric practice's role for individual with developmental disorders: current trend and future issues. Journal of Jpn Association of Psychiatric Hospitals 2009; 28: 14-20 (in Japanese).

14- Kay SR, Fischizophreniabein A, Opler LA. The positive and negative syndrome scale (PANSS) for schizophrenia. Schizophr Bull 1987; 13: 261.

15- Hamilton M. A rating scale for depression. J Neurol Neurosurg Psychiatry. Feb 1960; 23: 56-62.

16- Young RC, Biggs JT, Ziegler VE and Meyer DA. A rating scale for mania: reliability, validity and sensitivity. Br J Psychiatry 1978; 133: 429-35.

17- Howlin P, Moss P. Adults with autism spectrum disorders. Can J Psychiatry 2012; 57: 275-83. PMID: 22546059.

\section{Zagazig University Medical Journals}

18- Cochran DM, Dvir Y, Frazier JA. "Autismplus" spectrum disorders: intersection with psychosis and the schizophrenia spectrum. Child Adolesc Psychiatric Clin N Am 2013; 22: 609-27.

19- Abu-Akel A, Clark J, Perry A, Wood SJ, Forty L, Craddock N, Jones I, Gordon-Smith $\mathrm{K}$, Jones L. Autistic and schizotypal traits and global functioning in bipolar I disorder. J Affect Disord.; 2017; 207: 268-275. doi:10.1016/j.jad.2016.09.059.

20- Nylander L and Gillberg C. Screening for autism spectrum disorders in adult psychiatric out-patients: a preliminary report. Acta Psychiatr Scand: 2001; 103: 428-434.

21- 64- Wakabayashi A, Tojo Y, Baron-Cohen S, Wheelwright S: The Autism-Spectrum Quotient (AQ) Japanese version: evidence from high-functioning clinical group and normal adults [Abstract]. Shinrigaku Kenkyu 2004; $\quad 75 \quad$ (1): 78-84. http://www.ncbi.nlm.nih.gov/entrez/query.fcgi ?cmd $=$ Retrieve $\& \mathrm{db}=$ pubmed $\&$ dopt $=$ Abstract $\&$ list_uids $=15724518 \& q u e r y \_h l=5$

22- Daoud AO, Loughren M, Mansour K, Khashaba A. Autistic Traits in Individuals with Normal Intellectual Level and Associated Psychological Distress: A Pilot Study in an Arabic Culture. Published in health care 2015

How to cite this article: Dawoud KE, Raya YM, Yossef AM, Ibrahim AS. Detection of autistic like traits in patients with schizophrenia and bipolar disorders. ZUMJ 2019; 25 (1): 1-8. 